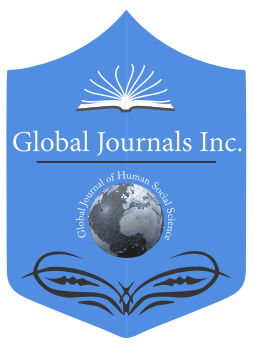

GLOBAL JOURNAL OF HUMAN-SOCIAL SCIENCE: A

ARTS \& HUMANITIES - PSYCHOLOGY

Volume 21 Issue 13 Version 1.0 Year 2021

Type: Double Blind Peer Reviewed International Research Journal

Publisher: Global Journals

Online ISSN: 2249-460X \& Print ISSN: 0975-587X

\title{
Spirituality among Health Professionals: An Exploratory Factor Analysis and a Moral Reflection
}

By Cristiane Paiva Alves, Lucas Guilherme Teztlaff de Gerone \& Paulo Sergio Macuchen Nogas

Universidade Federal de São Carlos

Abstract- Even nowadays, there are few studies about the use of quantitative methods about the practice of caring among healthcare professionals.

Objectives: To present a statistical analysis about spirituality, religiosity and health on the practice of caring between healthcare professionals. With the results found on the statistical analysis called exploratory factorial, there is a new reflection about spirituality and moral on the practice of caring that shows up, such as spirituality/religiosity on the life of healthcare professionals. The approach of spirituality/ religiosity in the care of the sick person and in the training of healthcare professionals; the positive impact of spirituality/ religiosity on the treatment of the sick person and spirituality/ religiosity on the practice of caring between pastoralist/ chaplains.

Methods: Quantitative survey-type research, classified and described as descriptive, applied to 89 (eighty nine) health professionals.

Keywords: spirituality. health professional.care. factor analysis. ethic.

GJHSS-A Classification: FOR Code: 929999



Strictly as per the compliance and regulations of:

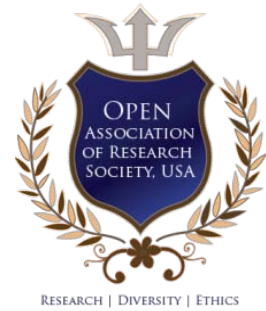

(c) 2021. Cristiane Paiva Alves, Lucas Guilherme Teztlaff de Gerone \& Paulo Sergio Macuchen Nogas. This research/review article is distributed under the terms of the Attribution-NonCommercial-NoDerivatives 4.0 International (CC BY-NC-ND 4.0). You must give appropriate credit to authors and reference this article if parts of the article are reproduced in any manner. Applicable licensing terms are at https://creativecommons.org/licenses/by-nc-nd/4.0/. 


\title{
Spirituality among Health Professionals: An Exploratory Factor Analysis and a Moral Reflection
}

\author{
A Espiritualidade Entre Os Profissionais Da Saúde: Uma Análise Fatorial \\ Exploratória E Reflexão Moral
}

\author{
Cristiane Paiva Alves ${ }^{\alpha}$, Lucas Guilherme Teztlaff de Gerone ${ }^{\sigma}$ \& Paulo Sergio Macuchen Nogas ${ }^{\circ}$
}

Resumo- Contexto: Há ainda poucos estudos que utilizam métodos quantitativos sobre a prática decuidado entre os profissionais da saúde.

Objetivo: Apresentar uma análise estatística sobre espiritualidade, religiosidade e saúde na prática do cuidado entre Profissionais de saúde. Com resultados encontrados na análise estatística denominada fatorial exploratória, reflete-se sobre a espiritualidade e a moral na prática do cuidado, como, a espiritualidade/ religiosidade na vida dos profissionais da saúde; A abordagem da espiritualidade/ religiosidade no cuidado da pessoa enferma e na formação dos profissionais da saúde; o impacto positivo da espiritualidade/religiosidade para o tratamento da pessoa enferma e a espiritualidade/ religiosidade na prática do cuidado entre o pastoralista/ capelão.

Métodos: Pesquisa quantitativa de tipo survey classificada como descritiva aplicada com 89 profissionais de Saúde. $\mathrm{Na}$

Author a: Possui doutorado em Educação Especial (Educação do Indivíduo Especial) pela Universidade Federal de São Carlos (2013), e Especialização em Terapia da Mão e Neurologia (2017), mestrado em Programa de Pós Graduação em Educação Especial pela Universidade Federal de São Carlos (2010) e bacharelado em Terapia Ocupacional pela Universidade Estadual Paulista Júlio de Mesquita Filho (2007). Desde 2014 é professora assistente doutora da Universidade Estadual Paulista Júlio de Mesquita Filho. É vice-líder do Grupo de Estudos e Pesquisas em Psicologia Moral e Educação Integral. Tem experiência na área de Terapia Ocupacional, Reabilitação e Educação, com ênfase biopsicossocial em saúde e educação e na Psicologia Moral.

Author $\sigma$ : Doutorando em Educação pela UNESP. Mestre em Teologia pela PUC/PR. Possui Especialização em Comportamento Organizacional; Especialização em Neuropsicopedagogia; Especialização em Filosofia e Sociologia; Especialização em Docência do Ensino Superior. MBAs em Administração e Gestão com ênfase na espiritualidade nas empresas. Graduado em Gestão comercial. Bacharelado em Teologia. Possui Licenciatura em Filosofia e Licenciatura em Pedagogia. É membro do Grupo de Estudos e Pesquisas em Psicologia Moral e Educação Integral UNESP Marília-SP; É pesquisador sobre a espiritualidade na área da saúde e na educação. É gestor do Instituto de Bem-Estar de Presidente PrudenteSOLIMED. e-mail: lucas.gerone@unesp.br

Author p: Doutor em Administração - PPAD-PUCPR (2010), Mestre em Tecnologia - PPGTE-UTFPR (2004), Especialista em Metodologia do Ensino Superior (1998), Graduado em Matemática - PUCPR (1994), laureado com o prêmio Marcelino Champagnat pelo melhor desempenho acadêmico da turma de 1994.Professor Titular da PUCPR. Coordenador de Avaliação Acadêmica, Assessoria Educacional,vice-reitoria da PUCPR. Atua principalmente nos seguintes temas: Coleta e Análise de Dados Quantitativos,Inovação, Decisões de Investimentos, Finanças Comportamentais.

e-mail:paulo.nogas@pucpr.br pesquisa utiliza-se o recurso da estatística multivariada denominada análise fatorial exploratória.

Resultados: A análise fatorial exploratória indicou que os profissionais da saúde acreditam na influência da espiritualidade/religiosidade na vida pessoal e na prática do cuidado com a pessoa enferma, reconhecendo a importância do pastoralista/capelão hospitalar. Os resultados encontrados na análise fatorial exploratória levatam e possibilitam as discussões que relacionam a espiritualidade/religiosidade as questões morais no contexto de saúde, como, a construção de valores na relação entre profissionais da saúde e a pessoa enferma, a prática de cuidado integral entre os profissionais da saúde, a busca da resiliência em meio ao sofrimento vivivenciado no contexto de saúde, e no cultivo da espiritualidade e da ética, em que se desenvolve afetividade e alteridade.

Consideraçôes: Faz-se necessária a continuidade do estudo com novas pesquisas interacadêmicas, com diversidade de técnicas estatísticas que contribuam com a análise da influência da espiritualidade e da religiosidade no contexto hospitalar, e na formação dos profissionais da saúde. A espiritualidade é vista como um fundamento e princípio ético capaz de influenciar e auxiliar nas tomadas de decisões das situações difíceis e de problemas da vida, como na construção de valores para a resiliência, na construção de valores de socialização na relação médica entre profissional da saúde paciente, na comunicação humanizadora, na construção do respeito e da empatia, na troca de experiências e autoconhecimento e na busca de cuidado humanizado que envolve dimensões espirituais e éticas, como a prática de cuidado do pastoralista/capelão que desenvolve-se na afetividade e alteridade.

Palavras-chave: espiritualidade. profissional de saúde. cuidado. análise fatorial. pastoralista. ética.

Abstract- Even nowadays, there are few studies about the use of quantitative methods about the practice of caring among healthcare professionals.

Objectives: To present a statistical analysis about spirituality, religiosity and health on the practice of caring between healthcare professionals. With the results found on the statistical analysis called exploratory factorial, there is a new reflection about spirituality and moral on the practice of caring that shows up, such as spirituality/religiosity on the life of healthcare professionals. The approach of spirituality/ religiosity in the care of the sick person and in the training of healthcare professionals; the positive impact of spirituality/ religiosity on the treatment of the sick person and spirituality/ 
religiosity on the practice of caring between pastoralist/ chaplains.

Methods: Quantitative survey-type research, classified and described as descriptive, applied to 89 (eighty nine) health professionals. On the research, it's used the multivariate statistics resource, called exploratory factorial analysis method.

Results: The exploratory factorial analyses indicated that healthcare professionals believe in the influence of spirituality/religiosity on the personal life and in the practice of caring with the sick person, acknowledging the importance of the hospital pastoralist/chaplain. The results found on the exploratory factorial analysis brings up and make possible the discussions that relate spirituality/religiosity to the moral perspectives on the health context, such as, the construction of values between the relation of healthcare workers/ professionals and the sick person, the practice of comprehensive healthcare among healthcare professionals, the search for resilience between the suffering experienced in the context of healthcare and in the cultivation of spirituality and ethics, in which affectivity and alterity are developed.

Considerations: It is necessary the continuity/permanence of studies with new academic researches, with diversity of statistics techniques that contribute with the analyses of the influence of spirituality and religiosity on the hospital context and in the formation/graduation of healthcare professionals. The spirituality is seen as a fundament and an ethical principle capable of influencing and aid the decision making of hard situations and life issues, in the construction of values for a perspective of resilience, in the construction of socialization values in the medical relation between healthcare professionals/workers, in the humanizing communication, in the construction of respect and empathy, in the exchanges and self-knowledge and in the search for a humanizing healthcare, that involves spiritual and ethics dimensions, like the practice of caring of the pastoralist/chaplain, that it's developed in the affectivity and alterity.

Keywords: spirituality. health professional.care. factor analysis. ethic.

\section{InTRODUÇÃO}

( urante a história da humanidade os temas espiritualidade/religiosidade, a moral e saúde estiveram interligados no trabalho dos profissionais da saúde. Nos últimos anos, as pesquisas do campo da saúde constatam que a religião é um fator psicológico e social poderoso, que influencia grandemente a saúde e as decisões da vida das pessoas (Koenig, 2012, p. 38). Os fatores psicológicos, sociais e religiosos estão ligados a uma reflexão moral (Gerone \& Bataglia, 2020). Como, na tomada de decisão referente à doação de sangue, à eutanásia, à cura, a práticas de cura, a medicamentos, à doação de órgãos, a questões sobre o direito de morrer, a procedimentos cirúrgicos e ao recebimento de visitas, nos conflitos vivenciados em uma situação de enfermidade entre pacientes e os profissionais da saúde (Gerone, 2015). Estes são alguns motivos pelos quais a "espiritualidade/religiosidade têm sido objeto de um crescente interesse entre clínicos e pesquisadores na área de saúde" (Moreira-Almeida, 2010, p. 18).

Apesar deste crescente, Gerone (2017, p.16) em uma revisão de literatura aponta que "há poucos estudos sobre a espiritualidade e religiosidade entre profissionais da saúde"que reflete sobre a questão moral na prática do cuidado. Como por exemplo, as tomadas de decisões referente ao estado de saúde e doença; a relação profissional com os pacientes e familiares em situação de vunerabilidade e morte; e as relações entre a equipe profissional; e a formação profissional.

Entre estes estudos levantados por Gerone (2017) nota-se que falta uma interdisciplinaridade metodológica entre qualitativo e quantitativo. De um lado, na área da saúde a maior parte dos estudos utiliza o método quantitativo. A medicina possui uma tradição histórica de pesquisa quantitativa e tem dificuldade de aceitar como estudo científico o método qualitativo (Turato, 2005, p.508). A psicologia, frequentemente utiliza escalas quantitativas para validar os estudos qualitativos (Bryman; \& Cramer, 1990, p. 40), tais como os estudos sobre o coping ${ }^{1}$ religioso/espiritual (Panzini, 2004, pp. 22-24).

Do outro lado, nos estudos da ciência da religião, o uso do método quantitativo é algo incomum. $\mathrm{Na}$ maior parte o objeto central dos estudos teológicos e da religião é de cunho abstrato, por exemplo quando se pesquisa sobre a fé, o que torna difícil uma quantificação (Gerone, 2017). Todavia, mesmo que a fé não seja quantificada, estuda-se quantitativamente os artifícios da fé, como os padrões de comportamento ${ }^{2}$ religiosos aos eventos relativos à saúde (Levin, 2003, p. 22).

Sendo assim, no presente estudo, aponta-se o resultado de uma pesquisa quantitativa com o uso da estatística multivariada, especificamente com a aplicação da análise fatorial exploratória sobre como os profissionais da saúde entendem a espiritualidade/ religiosidade na prática do cuidado hospitalar. Os resultados obtidos na análise fatorial foram interpretados qualitativamente por meio da técnica análise de conteúdo, tendo como referencial teórico a psicologia moral.

\footnotetext{
${ }^{1} \mathrm{O}$ coping é uma palavra derivada do inglês que não possui tradução literal em português, podendo significar "lidar com", "manejar", "enfrentar" ou"adaptar-se a" (PANZINI, 2004, p. 20). Coping são recursos pessoais constituídos por variáveis físicas e psicológicas que incluem a saúde física, a moral, e as crenças ideológicas (entre elas a religiosa e espirituais). Os recursos sócio-ecológicos, são encontrados no ambiente do indivíduo ou em seu contexto social, incluem relacionamento conjugal, profissional, características familiares, redes sociais, recursos funcionais ou práticos e circunstâncias econômicas (Beresford, 1994).Neste sentido, o coping têm se constituído em objeto de estudo da psicologia social, clínica e da personalidade.

2 Entende-se que estudar o padrão de comportamento envolve a dimensão moral (Leite, 2014).
} 
II. DEFINIÇÕES DAS TERMINOLOGIAS: Espiritualidade/Religiosidade, SaÚde, E A MORAL

De um lado, a religiosidade é uma qualidade daquilo que faz parte da religião, entendida a partir de sua etimologia latina, religare, que significa "religação" entre o homem e Deus (Derrida, 2000, p. 52). De acordo com Koenig (2012, p.11), religião é um sistema de crenças e práticas observado por um grupo de pessoas que se apoiam em rituais ou em um conjunto de escrituras e ensinamentos morais e religiosos "que reconhecem, idolatram, comunicam-se com ou se aproximam do Sagrado, do Divino, de Deus".

Do outro lado, a espiritualidade é uma dimensão existencial dinâmica, cultivada no espírito, que impulsiona o ser humano consciente em seus conhecimentos e escolhas vitais ${ }^{3}$, e que pode (ou não) estar relacionada à religião (Souza, 2013, p. 97). Para a médica Puchalski (2006, pp. 14-15), espiritualidade é:

A busca inerente de cada pessoa do significado e do propósito definitivo da vida. Esse significado pode ser encontrado na religião, mas, muitas vezes pode ser mais amplo do que isso, incluindo a relação com uma figura divina ou com a transcendência, relações com os outros, bem como a espiritualidade encontrada na natureza, na arte e no pensamento racional. Todos esses fatores podem influenciar o modo como a pessoa enferma e os profissionais da saúde percebem a saúde e a doença e como interagem uns com os outros.

A noção de saúde mais utilizada no meio acadêmico é da Organização Mundial de Saúde - que entende saúde como uma situação de completo bemestar físico, mental e social e em 1988, incluiu a dimensão espiritual no conceito multidimensional de saúde, trazendo reflexões acerca do sentido e significado da vida, passando assim a não limitar-se a sistemas de crenças ou práticas religiosas, em específico, mas, tratando espiritualidade como um conjunto de emoções e convicções de natureza não material, com a perspectiva o viver não pode ser claramente percebido ou compreendido, abrindo espaço para os mistérios da vida humana (Volcan, et al., 2003).

Para Scliar, esta noção busca expressar "uma vida plena" (2007, p. 37). Por isso, Luz (2013) afirma que se acrescentou a dimensão espiritual à noção de saúde, visto que a espiritualidade/religiosidade influencia toda a vida - os valores, os comportamentos (morais), a política, a economia, a cultura, a educação -, os quais se refletem diretamente na noção de saúde, ou seja, a vida que se deve viver para que seja possível cultivá-la. Dentro da esfera os deveres, nos

\footnotetext{
${ }^{3}$ Neste entendimento, a espiritualidade associa-se a noção de moral, enquanto um processo construção da consciência e decisões da vida.
}

remetemos à moral, que tem o significado advindo do latim mos - moris, que denota costume. Também entende-se como moral (mores) "a morada do ser", uma reflexão de prevalência ética, não somente de regras ou costumes, portanto uma moral ética ${ }^{4}$ (Boff, 2003).

A moral é um conjunto de normas e condutas elaboradas e aceitas por uma sociedade, em que se regula a relação social e o comportamento (Aulete, 1980). A moral também podem ser preceitos estabelecidos e admitidos que influenciam as crenças e os valores, dentre eles o religioso e o espiritual, bem como o modo de viver, como os hábitos diários relacionados à saúde. Neste sentido, a reflexão do que é moral associa diferentes condições humanas, ao estabelecer relações entre os valores das crenças religiosas com os hábitos de saúde que visam o desenvolvimento e a qualidade de vida, vícios e virtudes, e a busca de uma vida justa e feliz.

Neste sentido, La Taille (2006) diz que a moral se constitui em um sistema de regras e princípios que correspondem à pergunta "como devo agir?" e está intimamente relacionada à ética que busca responder a "que vida quero viver", se preocupando com a busca de uma vida boa e que vale a pena ser vivida.

Maior parte das tradições religiosas, recomendam fazer exercícios, manter a forma física, meditar, dormir o suficiente, tomar vacinas, ter disposição para passar por um exame médico, empreender uma peregrinação por razões de saúde, dizer a verdade a respeito de como se sente, ter esperanças de recuperação, combater o estresse, submeter-se a exercícios físicos e aconselhamentos e ser capaz de lidar com desenvoltura com uma deficiência física, demonstrando estarem de acordo com preceitos éticos e morais referente as suas crenças religiosas e a saúde (Levin, 2003).

\section{a) Área Da Saúde, Espiritualidade e a Moral}

Dentro da área da saúde no campo da psicologia encontra-se maior parte dos estudos e reflexão sobre a espiritualidade como uma prática de cuidado para encontrar a cura por intermédio de uma harmonia entre as dimensões somática (dos fenômenos corporais e da fisiologia), psicológica (dos instintos, condicionamentos e cognições) noética (do grego nous, que significa espírito) e da ética enquanto uma capacidade de pensar e agir sobre o estado de saúde e

\footnotetext{
${ }^{4}$ Neste estudo, entende-se a ética como uma noção associada a moral. Do grego "ethika", de "ethos", deriva dois entendimentos, modo de ser e o costume. Com o decorrer do tempo, de um lado, o entendimento do ser permanece como uma reflexão ética (morada do ser), do outro lado, o costume ("mores"), torna-se um conjunto de normas morais que regulam o comportamento humano. Na filosofia, a moral e a ética envolvem o estudo ou modo como viver, a busca do conhecimento e entendimento sobre os juízos morais ou de orientação moral (Boff, 2003).
} 
doença, como, as tomadas de decisões no tratamento médico (Gerone, 2015).

A influência da religiosidade sobre a saúde mental é um fenômeno resultante de vários fatores como: estilo de vida, suporte social, um sistema de crenças, práticas religiosas, formas de expressar estresse, direção e orientação espiritual (MoreiraAlmeida, Lotufo Neto, \& Koenig, 2006). Stroppa e Moreira-Almeida (2008) demonstram que muitos estudos apontam, em seus resultados, que maiores níveis de envolvimento religioso estão associados positivamente a indicadores de bem-estar psicológico, como satisfação com a vida, afeto positivo, felicidade, melhor saúde física e mental.

Lukoff (2003) mostra que muitas pesquisas revelam boas correlações entre saúde e espiritualidade. Portanto, existe a necessidade de incluir a espiritualidade como um recurso de saúde e a inclusão desta temática já na formação acadêmica, provocando reflexão e questionamento sobre a dimensão espiritual do ser humano.

Panzini e Bandeira (2005) dizem que vários estudos de saúde pública demonstram que pessoas que apresentam envolvimento religioso têm menor probabilidade de apresentar comportamentos de risco, como violência, delinquência e crime, o uso e abuso de substâncias que criam dependência como álcool e droga. Além disso, a grande maioria dos usuários de serviços de saúde, avaliados em 350 estudos científicos, quer ser perguntada sobre sua espiritualidade e/ou suas crenças religiosas no contexto do cuidado à saúde (Connelly \& Light, 2003).

Os estudos mostram a importância da espiritualidade para os usuários do sistema de saúde, e há na formação dos profissionais de saúde o preceito do cumprimento de princípios da Bioética ${ }^{5}$, como a autonomia, a não-maleficência, a beneficiência e a justiça, que quando seguidos na prática profissional, devem considerar as dimensões espirituais/religiosas dos usuários, assim como se consideram outras dimensões, como as biopsicosociais.

\section{ili. Metodologia}

A pesquisa foi realizada com 89 profissionais de saúde do Hospital Universitário Evangélico de Curitiba/PR $(H U E C)^{6}$. Utilizou-se como método a

\footnotetext{
${ }^{5}$ Entende-se como Bioética ("ética da vida") a ciência "que tem como objetivo indicar os limites e as finalidades da intervenção do ser humano sobre a vida, identificar os valores de referência racionalmente proponíveis, denunciar os riscos das possíveis aplicações". Para isso, a Bioética, utliza-se de uma metodologia interdisciplinar da educação, do direito, da sociologia, da economia, da teologia, da psicologia, da medicina (Leone; Privitera; Cunha, 2001).

${ }^{6}$ Foi formalmente requerida ao HUEC a assinatura de um termo de consentimento e aprovação para a realização da pesquisa.Também foi requerido a cada participante que assinasse um termo de consentimento livre e esclarecido.Obteve-se o parecer da aprovação
}

pesquisa quantitativa de tipo survey, classificada como exploratória e descritiva. Trata-se de um questionário com 35 perguntas, sendo 11 perguntas elaboradas em escala nominal e ordinal, 23 perguntas elaboradas em escala de Likert de 5 pontos ("discordo totalmente" a "concordo totalmente"7 e "totalmente falso" a "totalmente verdadeiro") e, ao final, umapergunta aberta.

As 35 perguntas foram divididas em cinco seções: seção I - dados sociobiodemográficos; seção II - noções de espiritualidade/religiosidade e o lugar desses conceitos na vida pessoal; seção III - relação entre espiritualidade/religiosidade e saúde; seção IV - coping religioso-espiritual do profissional; e seção V - integração da religiosidade e da espiritualidade no cuidado com o paciente. Nesta última seção, a pergunta 35, por ser aberta, permitiu aos profissionais da saúde relatar suas experiências de integração da espiritualidade/religiosidade na prática de cuidados em saúde.

As cinco seções do questionário foram elaboradas visando investigar o porquê e o como ocorre a integração da espiritualidade/religiosidade na prática do cuidado aos pessoa enferma entre os profissionais da saúde e pastoralistas. Portanto, cada seção possibilita uma discussão sobre o tema deste estudo.

O questionário foi elaborado e aplicado via Qualtrics. De acordo com Nogas (2011), Qualtrics é uma plataforma (software) que permite aos usuários criar seus questionários em ambiente web. Uma vantagem importante do questionário on-line é o fato de evitar consumo de papel. Utilizou-se um link de acesso da web que remetia ao questionárioefoienviado aos emails dos profissionais da saúde. Assim, cada resposta inserida passou a alimentar automaticamente a base de dados, evitando o consumo de papel,sema necessidade de digitação posterior, conferência, o que elimina a possibilidade de ocorrência de erros neste processo.

Os dados coletados pela Plataforma Qualtrics de gestão de questionários online, foram exportados e analisados no Statistical Package for the Social Science (SPSS), um programa de computador que permite análises estatísticas elementares e avançadas, como métodos multivariados, de forma rápida, tornando a interpretação conveniente para um usuário casual ou experiente (PEREIRA, 2006, p. 34).

do Comitê de Ética em Pesquisa da PUCPR, consubstanciado no $n^{\circ}$ 48582, em 2 de julho de 2012.

7 Encontra-se dificuldade de interpretação em algumas perguntas com as alternativas de "concordância/discordância"; neste caso, deveria ser em termos de "totalmente falsa/totalmente verdadeira", pois ostermos"concordância/discordância" podem dar margem à interpretação de outro tipo de pergunta, que poderia ser "concorda em perguntar". 


\section{Critérios da Coleta de Dados}

Para assegurar a confiabilidade do questionário aplicado aos profissionais da saúde, especialmente dos fatores ou construtos - agrupamentos de questões avaliou-se a sua consistência interna mediante cálculo do coeficiente Alpha de Cronbach. De acordo com Hair et al. (2005, p. 466), este coeficiente "é uma medida comumente usada de confiabilidade para um conjunto de dois ou mais indicadores de construto. Os valores variam entre 0 e 1 , as medidas mais altas indicam maior confiabilidade entre os indicadores". Conforme George e Mallery (2003), na interpretação dos valores do Alpha de Cronbachadotada-sea seguinte forma: a $>0,90=$ excelente; $a>0,80=$ bom; $a>0,70=$ aceitável; a $>0,60=$ questionável; $a>0,50=$ pobre; $a<0,50=$ inaceitável. O questionário aplicado aos profissionais da saúde gerou 4 fatores, que apresentaram Alfa de Chrobach entre 0,781 e 0,863, valores muito bons próximos de excelente.

Como se trata de um estudo exploratório optou-se por trabalhar com uma amostra que representasse no mínimo $10 \%{ }^{8}$ dos profissionais de cada uma das classes de profissionais da saúde do HUEC. Na obtenção da amostra calculada com tamanho um e meio $(1,5)$ considerou-se o tamanho dois (2).

Em determinas profissõespesquisadasobtevesema amostra de população maior que $10 \%$, por isso, aponta-se a quantidade de amostra coletada e o percentual representativo dentro da população total: 2 psicólogos/as representam $20 \%$ do total desta população; 63 enfermeiros/a ou técnicos/a em enfermagem, representam $10 \%$ do total desta população; 4 assistentes sociais representam $66 \%$ do total desta população; 3 fisioterapeutas representam $75 \%$ do total desta população; 3 fonoaudiólogos/as representam $100 \%$ do total desta população; 5 farmacêuticos/as representam $20 \%$ do total desta população; 2 nutricionistas clínicos representam 33\% do total desta população; 3 capelães/pastoralistas representam 23\% do total desta população; 5 médicos contratados representam $11 \%$ do total desta população (não se incluiu na amostra os médicos residentes, por serem terceirizados e o HUEC não ter a quantidade exata destes profissionais; portanto, a amostra concentra-se nos médicos contratados). Houve 16 profissionais que foram classificados como "outros", que são do administrativo, atendimento, recepção etc. Como o objetivo central da pesquisa são os profissionais da saúde, estes "outros" profissionais foram desconsiderados na presente análise.

\footnotetext{
${ }^{8} \mathrm{~A}$ amostra utilizada neste estudo é pequena e não aleatória, algo que limita os resultados e análise ao grupo estudado, ou seja, não permite extrapolação ou generalização.O ineditismo, entretanto, confere a sua relevância.
}

Foi desconsiderada a resposta de um profissional que assinalou a mesma alternativa em todas as perguntas desde a 13 até a 34 e na pergunta aberta relatou não ter interesse em responder. Restaram assim 89 respostas consideradas válidas para a análise. Para identificar a pergunta em discussão no texto, utiliza-se a letra maiúscula $\mathrm{P}$ e o número da pergunta entre parênteses, de acordo com as seções do questionário - por exemplo: (P10). ${ }^{9}$

\section{Sobre o Instrumento Para a Análise}

\section{DA Pesquisa}

Como se trata de uma pesquisa descritiva eexploratória, utiliza-se a Análise Fatorial Exploratória AFE como umrecurso para análise das respostas obtidas com o questionário. De acordo com Espinoza (2003, p. 106), a AFE éum procedimento estatístico multivariado, que identifica variáveis altamente correlacionadas, agrupando-as em fatores ou construtos. Considera-se que cada pergunta do questionário avalia a percepção dos respondentes a respeito de uma variável observável. De acordo com semelhanças nos padrões de resposta observados nas diversas variáveis (perguntas do questionário), foram identificados os fatores, os quaissão entendidos como construto se, depois de avaliadas suas relevâncias estatísticas, são interpretados à luz da teoria que fundamenta o estudo.

Para aplicar a análise fatorial é necessário averiguar se a matriz de dados é apta para este tipo de tratamento (Damasio, 2012, p.215). Para isso, utilizamse dois critérios: o primeiro é o critério de Kaiser-MeyerOlkin (KMO), também, conhecido como "Medida de Adequação da Amostra", uma medida para quantificar o grau de intercorrelações entre as variáveis comum valor entre zero e um (Hair et al, 2005, p. 98). Para Hair et al (idem), um valor menor que 0,5 é considerado inaceitável para aplicar a AFE. Valores entre 0,5 e 0,7 não são relevantes estatisticamente. Valores entre 0,7 e 0,8 são considerados muito bons. Valores entre 0,8 e 0,9 são considerados excelentes. No questionário aplicado aos profissionais da saúde o valor obtido do teste de KMO é 0,766o que os autores pesquisados consideram um valor muito bom. O segundo critério é o teste de esfericidade de Bartlett, que avalia a significância de todas as correlações em uma matriz de dados (Hair et al, 2005, p. 98).

Para Hair et al (2005, p. 91), "valores do teste de esfericidade de Bartlett com níveis de significância inferiores a $5 \% \quad(p<0,05)$ indicam que a matriz é "fatorável" e que se pode prosseguir com a AFE. No questionário aplicado aos profissionais da saúde o valor

\footnotetext{
${ }^{9}$ É possível visualizar todo o questionário disponível: http://www. biblioteca.pucpr.br/tede/tde busca/arquivo. php?codArquivo=3116
} 
obtido no teste de Bartlett indicou $p<0,001$, ou seja, a matriz de dados obtida é fatorável e pode-se prosseguir com a análise.

Posterior aos testes $\mathrm{KMO}$ e Bartlett - métodos de retenção ${ }^{10}$ aplicou-se um método de rotação ${ }^{11}$ ortogonal varimax ${ }^{12}$. De acordo com Espinoza (2003, p. 107), essa rotação relaciona os fatores distintos e não correlacionados e, assim, simplifica a interpretação dos fatores que não estejam claros, ou seja, melhora interpretação dos resultados à luz do significado das variáveis sem afetar as relações entre eles.

\section{Resultados da Análise Fatorial}

$\mathrm{Na}$ condução da AFE sobre as respostas a um conjunto de questões respondidas pelos 89 profissionais da saúde ${ }^{13}$, se obteve como resultado quatro fatores: no primeiro fator congregam-se questões em torno da espiritualidade/religiosidade na vida dos profissionais da saúde; no segundo, sobre a abordagem da espiritualidade/religiosidade no cuidado as pessoas enfermas na formação dos profissionais da saúde; no terceiro, sobre o impacto positivo da espiritualidade/religiosidade para 0 tratamento dapessoa enferma; e no quarto, sobre a espiritualidade/ religiosidade na vida dos profissionais da saúde. Os quatro fatores possuem uma variância explicada de $64,99 \%$. Isto significa que os quatro fatores identificados conseguem representar $64,99 \%$ das informações constantes nas 17 perguntas que apresentaram padrões de resposta semelhantes e permitram agrupamento. De acordo com Hair et al (2005, p.106), valores superiores a 50\% são considerados satisfatórios. O primeiro fator contribui com $21,759 \%$; o segundo com $19,854 \%$; o terceiro com $12,89 \%$; e o quarto com $10,483 \%$. Os quatro fatores encontrados representam 17 das 23 perguntas do questionário, que foram elaboradas usando a escala de Likert de 5 pontos, perguntas fechadas com opções de respostas: discordo totalmente a concordo totalmente e totalmente falso a totalmente verdadeiro.

A AFE permitiu agrupar em fatores as perguntas mais relevantes de quatro das cinco seções do questionário. Por isso agrupam-se, em cada um dos quatro fatores, duasou mais perguntas, conforme um indicador denominado fator de carregamento. É desejável que seu valor seja, ao menos, próximo de 0,5; quanto maior, mais forte é a correlação da pergunta com o seu respectivo fator e maior é o percentual de variância explicada (HAIR et al, 2005, p. 107).

\section{Vil. Discussão da AnÁlise Fatoral e Reflexão MORAL}

Os quatro fatores encontrados na análise foram nomeados de acordo com a peculiaridade de correlação das perguntas (variáveis). São eles:

Fator 1: A espiritualidade/religiosidade na vida dos profissionais da saúde

\begin{tabular}{|l|c|}
\hline \multicolumn{1}{|c|}{ Questões originais } & Carregamento \\
\hline $\begin{array}{l}26 \text { - frequentemente utilizo minhas crenças religiosas-espirituais para lidar } \\
\text { com situações difíceis em minha vida. }\end{array}$ & 0,861 \\
\hline $\begin{array}{l}25 \text { - em tempos de sofrimento ou dificuldade em minha vida, minha } \\
\text { religiosidade-espiritualidade me ajuda lidar com a situação. }\end{array}$ & 0,825 \\
\hline $\begin{array}{l}27 \text { - a oração/reza é uma prática que utilizo quando enfrento problemas no } \\
\text { trabalho. }\end{array}$ & 0,79 \\
\hline $\begin{array}{l}17 \text { - em minha vida, eu sinto a presença divina (ou, do sagrado, de uma } \\
\text { energia cósmica, de um ser superior, de deus, do espírito santo, ou de } \\
\text { algo maior que eu). }\end{array}$ & 0,738 \\
\hline $\begin{array}{l}16 \text { - a espiritualidade me ajuda a manter minha vida equilibrada e estável } \\
\text { do mesmo modo como minha cidadania, minhas amizades, e minha } \\
\text { participação em outros grupos me ajudam. }\end{array}$ & 0,69 \\
\hline 15 - toda a minha vida fundamenta-se em minha espiritualidade. & 0,658 \\
\hline
\end{tabular}

\footnotetext{
${ }^{10}$ Busca-se fazer a retenção de itens quecontêm informação importante para avaliar o construto sob investigação. Veja: LAROS, J. A. "O uso da análise fatorial: algumas diretrizes para pesquisadores". In: L. Pasquali (org.). Análise fatorial para pesquisadores. Brasília: Lab PAM, Editors, 2005, p. 171.

11 O objetivo do processo de rotação é conseguir uma estruturafatorial simples. Uma estrutura simples é alcançada quando cada variável, preferencialmente, tem uma única carga alta em um único fator. Veja: LAROS, J. A. "O uso da análise fatorial: algumas diretrizes para pesquisadores". In: L. Pasquali (org.). Análise fatorial para pesquisadores. Brasília: LabPAM, Editors, 2005, p. 184.

${ }^{12} \mathrm{O}$ objetivo de Varimax é maximizar a variância das cargasfatoriais para cada fator por meio do aumento das cargas altas e da diminuiçãodas cargas baixas. LAROS, J. A. "O uso da análise fatorial: algumas diretrizes para pesquisadores". In: L. Pasquali (org.). Análise fatorial para pesquisadores. Brasília: LabPAM, Editors, 2005, p. 185.

${ }^{13}$ Apesar da amostra utilizada neste estudo ser pequena, algo que limita os resultados da análise fatorial ao grupo estudado, ou seja, não permite extrapolação ou generalização, de todo modo, a opção pela análise fatorial se deu por se tratar de um estudo exploratório.
} 
Neste fator, agrupam-se perguntas correlacionadas com o impacto positivo da espiritualidade/religiosidade na vida dos profissionais de saúde. Na AFE nenhuma pergunta relacionada à questão negativa da espiritualidade/religiosidade na vida dos profissionais de saúde apresentou correlação significativa com outra a ponto de gerar um novo fator (construto).

Procedeu-se o teste Alfa de Chronbach, que resultou em 0,863, denotando elevada validade interna do construto, indicando que as semelhanças nos padrões de resposta são efetivas do ponto de vista estatístico. Além disso observa-se que isso se confirma tambéma partir do ponto de vista conceitual já estudado no presente trabalho.

As perguntas do fator 1 estão relacionadas a espiritualidade (P15, P16 e P17) e a religiosidade (P25, P26 e P27) dos profissionais da saúde, o que confirma a relação entre as noções da espiritualidade com a religiosidade. Para os profissionais da saúde a espiritualidade é vivida e entendida por meio da religiosidade como uma dimensão da transcendência humana, presente na vida, sentida como presença divina ou do sagrado, de uma energia cósmica, de um ser superior, de Deus, do Espírito Santo ou de algo maior que o ser humano (P17).

A pergunta mais relevante do fator se refere ao uso conjunto das crenças religiosas e espirituais (P26). A segunda pergunta mais relevante une a religiosidadeespiritualidade como uma forma de lidar com o sofrimento pessoal (P25). Na terceira pergunta mais relavante (P27) entende-se que a orção/reza, uma prática religiosa, é uma forma para lidar com as situações difíceis e o sofrimento. As três ultimas peguntas (P15, P16, P17) aparecem próximas na classificação de relevância e dão mais ênfase a noção de espiritualidade associada ao fundamento da vida
(P15), o que remete ao sentido da vida; a cidadania (P16), o que remete ao comportamento social, aos direitos e deveres, ao de ter acesso à saúde, moradia, alimentação e educação; a socialização através das amizades e grupos sociais; e a transcendência como algo maior, superior, cósmico (P17).

Considera-se que a espiritualidade relaciona-se as questões existenciais, e se expressa na religiosidade e a moral, como por exemplo, o uso da espiritualidade/religiosidade para entender e lidar com as situações difíceis, sofrimento e problemas na vida pessoal e profissional.

Neste sentido, a espiritualidade é vista como um fundamento e princípio ético capaz de influenciar e auxiliar nas tomadas de decisões das situações difíceis e problemas da vida, como a construção de valores para a resiliência encontrada no coping religioso e espiritual como um recurso de enfrentamento e resiliêncianas adversidades da vida pessoal e profissional, como, na adapatação e mudanças a espiritualidade torna-se instrumento de significação através do otimismo, controle de impulsos e emoções, análises do ambiente, empatia, autoeficácia (Job, 2003).

Sobre o feito do coping religioso e espiritual como resiliência não foram encontradas perguntas de impacto negativo no fator 1 , oque confirma o uso do coping religioso e espiritual positivo. Os profissionais da saúde vêm a espiritualidade/religiosidade como algo mais positivo do que negativo e que proporciona um ambiente de trabalho saudável e harmonioso e ético, com menos estresses e conflitos, realização pessoal e resiliência, e na construção de valores de socialização na relação médica entre profissional da saúde paciente, como, a comunicação humanizadora, o respeito e a empatia, a troca de experiências e autoconhecimento (Gerone, 2015).

Fator 2: A abordagem da espiritualidade/religiosidade no cuidado apessoa enferma na formação dos profissionais da saúde

\begin{tabular}{|l|c|}
\hline \multicolumn{1}{|c|}{ Questões originais } & Carregamento \\
\hline $\begin{array}{l}\text { 31 - profissionais da saúde deveriam receber formação sobre como abordar as } \\
\text { questões religiosas-espirituais durante o tratamento. }\end{array}$ & 0,784 \\
$\begin{array}{l}30 \text { - frequentemente pergunto apessoa enferma sobre questões religiosas ou } \\
\text { espirituais. }\end{array}$ & 0,733 \\
$\begin{array}{l}32 \text { - sinto-me confortável em abordar questões religiosas-espirituais durante o } \\
\text { processo de tratamento. }\end{array}$ & 0,723 \\
$\begin{array}{l}28 \text { - é importante ter conhecimento de questões relativas à religiosidade ou } \\
\text { espiritualidade do paciente no tratamento de saúde... } \\
29-\text { aspessoas enfermas gostariam de trazer as questões religiosas-espirituais } \\
\text { para o tratamento. }\end{array}$ & 0,681 \\
24 - é importante reconhecer as necessidades espirituais dapessoa enferma. & 0,679 \\
\hline
\end{tabular}

O Teste de validade interna do construto representado pelo Fator 2 - Alfa de Chronbach - resultou em 0,823, indicando que as semelhanças nos padrões de resposta são efetivas do ponto de vista 
estatístico. Assim como no Fator 1, observa-se que esta relação se confirma também a partir do ponto de vista conceitual relacionado a estas questõesno presente trabalho e em estudos anteriores.

Neste fator há correlações de perguntas sobre a abordagem da espiritualidade/religiosidade no tratamento da pessoa enferma. A pergunta com maior fator de carregamento do fator é a de receber formação sobre como abordar a questão espiritual e religiosa no tratamento (P31). De um lado, a abordagem da espiritualidade/religiosidade no tratamento dapessoa enferma está correlacionada com o fato de os profissionais da saúde receberem formação sobre esta temática.

Por outro lado, na segunda e na terceira perguntas com maior fator de carregamento do fator, os profissionais que declararam se sentir confortáveis em abordar a questão espiritual e religiosa no tratamento (P32) também realizam com frequência (P30) estas perguntas. Neste sentido, entende-se que a formação pode ajudar o profissional a se sentir mais confiante ou mais preparado para abordar tal questão.

De fato, em outra pergunta correlacionada a este mesmo fator, os profissionais responderam sobre a importância de se ter o conhecimento sobre a questão religiosa e espiritual no tratamento de saúde (P28). Portanto, mesmo para os profissionais que já abordam esta questão com frequência no tratamento, ainda assim é importante se ter um conhecimento sobre isto. Neste sentido, este conhecimento se correlaciona com a formação sobre a questão espiritual e religiosa no tratamento.

Ainda, vale ressaltar a correlação entre as perguntas que tratam de receber formação sobre como abordar a questão espiritual e religiosa no tratamento (P31) e da importância de ter conhecimento sobre esta questão no tratamento de saúde (P28) com reconhecer as necessidades espirituais e religiosas da pessoa enferma (P24) e se estes gostariam de trazer estas necessidades para o tratamento (P29). Neste contexto, considera-se que a formação e o conhecimento sobre a espiritualidade/religiosidade pode ajudar os profissionais da saúde a reconhecer a necessidade espiritual e religiosa da pessoa enferma e identificar se estes gostariam de trazer isso para o tratamento. Em geral, os profissionais da saúde que apresentam concordância com uma destas questões concordam também com as demais e, portanto, podem abordar a espiritualidade/religiosidade da pessoa enferma.

Entre os estudos de Lind, em uma pesquisa com estudantes de medicina encontra-se uma regressão na competência ${ }^{14}$ do julgamento moral

\footnotetext{
${ }^{14}$ Para Bataglia (2020) a competência morl é "a capacidade de agir de modo ético" (p.14), "uma habilidade que se evidencia no social, em situações de conflito e que conjuga aspectos diversos da personaldade: emoções, sentimentos, atitudes, $r$ azão, disposição" (p.18).
}

(C--score), que deve estar relacionada ao ambiente de aprendizado médico (Bataglia, 2020). De acordo com Gerone (2015) a formação dos profissionais da saúde visa mais o lado científico e biomédico devido à separação entre a ciência e a religião. Na Idade Média, por influência da Igreja Católica, associava-se a o tratamento médico com as crenças morais religiosas ${ }^{15}$, como por exemplo, o poder da cura de uma enfermidade estava em Deus, e a doença ${ }^{16}$ era um resultado do pecado e da imoralidade humana. ${ }^{17}$ Devido a isto, e ao avanço científico na Idade Moderna $^{18}$, a formação médica torna-se científica e técnica, em que a relação entre a ciência e a religião passou a ser visto como algo artesanal. Surge, então, um modelo de tratamento médico técnico (Gerone, 2015).

$\mathrm{Na}$ contemporaneidade, a formação técnicacientífica na área médica é discutida. Os enfoques técnicos através da tecnologia e das pesquisas científicas possibilitam curar e tratar enfermidades que em séculos passados eram incuráveis, e assim, proporcionam melhorar qualidade de vida. Contudo, o uso indiscriminado da tecnologia ainda com boas intenções pode resultar no abandono, muitas vezes não intencional, de outras dimensões humanas respeitáveis, como, a comunicação, os valores, a dignidade do ser, os sentidos e propósitos existenciais (Gerone, 2015). Neste sentido, busca-se na formação médica uma visão integral, que abarca a dimensão psicológica, social, ecológica e espiritual (Bataglia, 2020).

\footnotetext{
${ }^{15}$ No início da era cristã até a alta Idade Média, há uma forte crença no poder milagroso do evangelho para curar as doenças. O texto lucano relata o cuidado em saúde como algo profundamente característico a Cristo: "[...] toda a multidão procurava tocar-Ihe, porque saía dele virtude, e curava a todos" (Lc 6.19).

${ }^{16}$ A saúde está na valorização do sofrimento e da enfermidade. Acreditavam que Deus salvava apenas pela experiência do sofrimento e da enfermidade, pois um corpo sadio não é com frequência um lugar habitado por Deus (GERONE, 2015).

17 O povo hebreu acreditava que a doença era causada pelo pecado e a saúde ao obedecer a Deus (Gn12:17; Pv 23:29-32). Este pensamento compõe a visão judaico-cristã fortemente na idade Média. Atualmente, percebem-se alguns grupos religiosos com o mesmo pensamento, como por exemplo, o neo pentecostal (Gerone, 2015).

${ }^{18} \mathrm{O}$ foco tecnológico e prestação de serviços são advindos da Revolução Industrial (Gerone, 2015).
} 
Fator 3: O impacto positivo da espiritualidade/religiosidade para o tratamento da pessoa enferma

\begin{tabular}{|l|c|}
\hline \multicolumn{1}{|c|}{ Questões originais } & Carregamento \\
\hline $\begin{array}{l}21 \text { - a religiosidade do paciente (tais como oração, reza, meditação, frequência a um } \\
\text { grupo religioso) coopera no tratamento }\end{array}$ & 0,859 \\
22 - a espiritualidade do paciente tem influência positiva em seu tratamento. & 0,848 \\
$\begin{array}{l}23 \text { - é importante para o profissional da área da saúde compreender melhor a relacão } \\
\text { entre saúde e espiritualidade. }\end{array}$ & 0,568 \\
\hline
\end{tabular}

A validade interna do construto representado pelo Fator 3 foi validada pelo Teste Alfa de Chronbach que resultou em 0,783 , indicando que as semelhanças nos padrões de resposta são efetivas do ponto de vista estatístico. Como já observado no Fator 1 e no Fator 2, do mesmo modo aqui é possível depreender que esta relação se confirma também a partir do ponto de vista conceitual relacionado a estas questões no presente trabalho e em estudos anteriores.

Porém, de um lado, o fator agrupa uma pergunta que não é específica sobre o impacto positivo ou negativo da espiritualidade/religiosidade no tratamento, mas refere-se à importância dos profissionais da saúde compreender melhor a relação entre saúde e espiritualidade (P23). Nesse sentido, considera-se que "compreender melhor" pode também remeter aos impactos causados pela relação entre espiritualidade/religiosidade e saúde, sejam eles positivos ou negativos, os quais são inevitáveis no tratamento da pessoa enferma, tendo em vista, por exemplo, as diferentes óticas das pessoas enfermas, dos familiares e dos profissionais sobre a relação da saúde com as crenças e práticas religiosas ou espirituais. Diante disto, entende-se que compreender melhor o impacto da espiritualidade remete a uma questão ética, como por exemplo, os direitos a dignidade da pessoa enferma e familiares que podem ser fundamentados nas crenças morais religiosas, tais como, não tomar determinada medicação ou aderir um tratamento médico que não condiz com os fundamentos da vida e os princípios religiosos.

Portanto, a espiritualidade enquanto uma dimensão ética no contexto de saúde entra no reconhecimento do direito de autodeterminação da pessoa enferma, nos conflitos com do paternalismo médico que detem uma certa competência exclusiva do saber sobre o que seria o melhor ou bem é preciso relevar que ninguém goza de saúde completa se não puder responder à pergunta: saúde pra quê? Não se vive para ser saudável, mas é saudável para viver e agir. Ou seja, a pessoa enferma pode por meio da prática de cuidado ser curada, mas não ter saúde integral se este processo de cura fere sua ética e crenças, tais como as religiosas e espirituais. É preciso, portanto, compreender que a prática do cuidado passa por olhares não somente técnicos, mas, envolve também, espirituais e éticos.

Os dados do fator 3 apontam que quando os profissionais da saúde valorizam a espiritualidade/ religiosidade enquanto princípios e valores da pessoa enferma na prática do cuidado obtem impacto positivo extremamente relevantes. A pergunta com a maior relevância refere-se ao efeito positivo da religiosidade (oração, meditação e frequência a um grupo religioso) no tratamento da pessoa enferma (P21). A segunda pergunta mais relevante refere-se à influência positiva da espiritualidade no tratamento (P22). Ou seja, as altas relevâncias destas perguntas como as mais relacionadas ao fator em questão podem indicar que os profissionais estão convictos de que há um maior impacto positivo da espiritualidade/religiosidade no tratamento dapessoa enferma.

Ainda, percebe-se que a pergunta 21, referente à influência da "religiosidade" (oração, meditação e frequência a um grupo religioso) para o tratamento dapessoa enferma, tem um maior peso na definição deste fator, quando comparada com a pergunta 22, que se refere à influência positiva da "espiritualidade" no tratamento. Dentro deste contexto, pode-se depreender que, para os profissionais da saúde, a espiritualidade da pessoa enferma ocorre mediante as práticas religiosas: oração, meditação e frequência a um grupo religioso. A composição do fator parece, ainda, indicar que para estes profissionais, a espiritualidade não é uma noção própria, mas algo derivado da religiosidade. Ressalta-se isto pelo fato de que esta compreensão da espiritualidade como algo derivado da religiosidade pode interferir tanto positiva como negativamente na abordagem da espiritualidade/religiosidade no tratamento dapessoa enferma. Por exemplo, um paciente que apresenta a necessidade de ter um cuidado espiritual, de um lado, pode se sentir mais bem amparado afetivamente se receber juntamente neste cuidado práticas religiosas, como orações, meditações e outras. De outro lado, pode também ter a sensação de estar sendo desrespeitado (ato imoral) por causa de uma imposição religiosa ou insatisfação com a abordagem religiosa realizada no cuidado. Portanto, 
neste contexto, mesmo que a espiritualidade seja derivada da religiosidade e positiva para o tratamento, cabe aos profissionais da saúde considerar na abordagem tanto a questão da religiosidade como da espiritualidade. Pois, não se trata apenas de uma questão religiosa, mas ética. Quando os profissionais da saúde forem indiferentes quanto à religiosidade/ espiritualidade dos pacientes, podem ferir e desrespeitar a sua dignidade ou agravar seus conflitos religiosos, o que pode influenciar negativamente seu estado de saúde. Portanto, valoriza as crenças religiosas e espirituais propocina melhoria no tratamento, um cuidado humanizado, na dignidade e no sentido de vida mesmo em uma situação de sofrimento ou conflito. Isto tornase um ato saudável na medida em que não se limita a saúde apenas em ter (ou não) uma enfermidade. Mas a pessoa enferma é vista em sua integralidade. Uma prática de cuidado que representa o comprimisso ético com a vida e todas suas manifestações e experiências, seja, elas religiosas e espirituais.

Fator 4: A espiritualidade/religiosidade na prática do cuidado entre os pastoralista/capelão

\begin{tabular}{|c|c|}
\hline \multicolumn{1}{|c|}{ Questões originais } & Carregamento \\
\hline $\begin{array}{l}\text { 33 - considero importante a atuação de um pastoralista ou líder religioso } \\
\text { atendendo necessidades espirituais dapessoa enferma no meio hospitalar. }\end{array}$ & 0,891 \\
\hline $\begin{array}{l}34 \text { - eu encaminharia um paciente a um pastoralista ou líderreligioso caso este } \\
\text { fosse apto para fazer atendimentos religiosos e espirituais. }\end{array}$ & 0,816 \\
\hline
\end{tabular}

Procedeu-se o teste Alfa de Chronbach, que resultou em 0,781 , denotando elevada validade interna neste construto, assim como se observou nos três construtos anteriores. Isso indica que as semelhanças nos padrões de resposta são efetivas do ponto de vista estatístico. É muito relevante observar que isso também se confirma também a partir do arcabouço teórico e conceitual estudado, indicando relevância das presentes constatações.

Neste fator encontram-se duas perguntas altamente relevantes sobre a atuação de um pastoralista/capelão ${ }^{19}$ no ambiente hospitalar. Uma delas se refere à importância da atuação do pastoralista/c apelão para atender às necessidades espirituais dapessoa enferma (P33). A outra se relaciona ao profissional de saúde e se ele encaminharia um paciente a um pastoralista ou líder religioso caso este fosse apto para fazer atendimentos religiosos e/ou espirituais (P34). Considerando a correlação entre estas perguntas, analisam-se os seguintes pontos:

1) Percebe-se que a pergunta 33 se refere à atuação de um pastoralista/capelão (a maior parte deles é cristã) ou líder religioso (qualquer religião); portanto, há dois sujeitos. Na maioria das vezes, o

\footnotetext{
19 o serviço de capelania consiste em um ministério de apoio espiritual, social e emocional que colabora na formação integral do ser humano por meio de atitudes concretas: presença, gestos, palavras, orações, textos sagrados, música, silêncio e fortalecimento, aconselhamento e consolação em horas de angústia e incerteza junto aos enfermos, às famílias de enfermos e às equipes de saúde. funções do capelão/pastoralista inclui-se a de resgatar a dimensão humana por meio da religiosidade/espiritualidade e ser um auxiliador diante do sofrimento, ao transmitir uma presença solidária, afetiva e fratenal por meio do consolo e da esperança existentes em elemento transcendente (Gerone, 2015).
}

pastoralista/capelão também é um líder religioso, como, por exemplo, o pastor ou padre que realiza ações pastorais no ambiente hospitalar. Já o líder religioso não precisa necessariamente ser um pastoralista/capelão para realizar o atendimento espiritual e religioso da pessoa enferma. Porém, para os profissionais da saúde, tanto o pastoralista/capelão quanto o líder religioso precisa ser apto para fazer o atendimento religioso e espiritual, ou seja, ter um preparo ou uma formação teórica e prática sobre isto.

2) Como na maioria dos hospitais, no HUEC cada profissional possui uma atribuição específica de afazeres. Neste contexto, o atendimento religioso e espiritual à pessoa enferma faz parte das atribuições do pastoralista/capelão. Por isso, tornase importante a sua atuação no ambiente hospitalar, pois o pastoralista/capelão é o profissional apto para realizar o atendimento espiritual e religioso a pessoa enferma que são encaminhados pelos profissionais da saúde.

3) O elevado fator de carregamento observado nas perguntas com foco no pastoralista/capelão e no atendimento espiritual e religioso pode ser pelo fato de que, além de atender a pessoa enferma, o pastoralista/capelão pode prestar atendimento espiritual e religioso aos profissionais da saúde. De fato, a espiritualidade/religiosidade é um recurso que ajuda os profissionais da saúde a lidar com problemas da vida e realizar melhor o seu trabalho.

Um dos maiores desafios destes profissionais que evidencia-se em um conduta ética é preservar a vida (Backes D; Lunardi V; Lunardi W, 2006). Porém, mesmo lidando com certa frequência com questões difíceis, comunicar um prognóstico negativo ao 
paciente ou óbito aos familiares colocam esses profissionais diante de tarefas difíceis. Em muitas destas experiências há um sentimento de fracasso por não ter preservado a vida, ou de espelho e projeção imagem de si próprio na mesma situação. Por isso, os profissionais da saúde que assistem pacientes graves no limiar da morte ou em situação de sofrimento precisam, também, ter um acompanhamento dentro dos moldes da psicologia e da religião. O pastoralista/capelão procura zelar pela vida dos profissionais da saúde que vive, pensa, sente e é afetado por forças e ideologias de morte.

No acompanhamento aos profissionais da saúde, o pastoralista/capelão desenvolve uma prática de cuidado pautada no cultivo da espiritualidade e da ética, através da afetividade e alteridade, procura estar próximo, em comunhão, assistindo, nutrindo, manifestando a esperança e confiança, consolo (Artigas, 2008). Elementos e fontes de inspiração motivadora de atitudes transformadoras, em que nada é excluído. Tudo aponta para um contexto de saúde integral e humanizadora: a vida e a morte, a doença e a cura, o corpo e o que nele acontece. Uma postura diante dos eventos de saúde e doença que eleva a condição humana, pois, diante do sofrimento, morte e doença nem tudo se torna necessariamente patológico, pode ser até terapêutico e saudável, ou ser vivido de forma ética, onde os valores morais, religiosos e espirituais significam o sentido da vida.

\section{Considerações}

Depreende-se que as técnicas quantitativas estatísticas aplicadas neste estudo não têm a pretensão de substituir as análises qualitativas. De acordo Gerone (2015. p.40) a maioria dos estudos sobre espiritualidade e saúde não utilizam técnicas quantitativas, de modo que o presente trabalho pode ser considerado uma inovação na exploração da temática, tanto na descoberta de dados como na possibilidadede novas pesquisas que envolvam métodos qualitativos e quantitativos.

Especificamente o fenômeno deste estudo: espiritualidade/religiosidade e moral não podem ser quantificadas, todavia, podem-se analisar estatisticamente padrões de comportamentos e crenças dos profissionais da saúde sobre a influência dos fenômenos religiosos e espirituais nos eventos relativos à saúde. Neste contexto, considera-se que as analises estatística e fatorial deste estudo:

a) Permitiram agrupar em fatores as perguntas mais relevantes das cinco seções do questionário, facilitando a interpretação dos dados e possibilitando uma reflexão moral sobre os resultados encontrados.

b) Dar confiabilidade e relevância acadêmica para pesquisa tanto para área da saúde: medicina, enfermagem, psicologia, como para área religiosa: teologia, ciência da religião.

Em segundo momento, sobre a espiritualidade/ religiosidade na prática do cuidado entre profissionais da saúde a análise estatística e fatorial demonstram:

a) De acordo com os resultados da AFE sobre as questões respondidas, a espiritualidade é uma noção que ocorre dentro da religiosidade através de práticas religiosas, tais como, a oração, que aparece no uso do coping para enfrentar as situações adversas da vida e no ambiente de trabalho. Na AFE o coping religioso espiritual é um recurso positivo para o enfretamento e resiliência. Não foram encontradas perguntas de impacto negativo na $A F$, oque confirma que os profissionais da saúde vêm a religiosida-de/espiritualidade como algo mais positivo do que negativo. Sendo, portanto, a espiritualidade um recursoimportante para uma prática de cuidado mais humanizadora, integral e ética que ajuda a lidar e entender as situações de conflitos, sofrimento, dor vivenciados no contexto de saúde.

b) Os problemas de saúde fazem com que as pessoas se voltem para a religião, tendo uma relação entre a religiosidade e saúde. O que tem um impacto moral, como, nas tomadas de decisões sobre o estado de saúde e doença. Ainda, os profissionais da saúde concordam que a espiritualidade do paciente tem influência positiva em seu tratamento.

c) As perguntas sobre o impacto positivo da espiritualidade/religiosidade no tratamento da pessoa enferma são extremamente relevantes. A pergunta com a maior relevância refere-se ao efeito positivo da religiosidade (oração, meditação e frequência a um grupo religioso) no tratamento da pessoa enferma. Dentro deste contexto, pode-se depreender que, para os profissionais da saúde, a espiritualidade da pessoa enferma ocorre mediante as práticas religiosas: oração, meditação e frequência a um grupo religioso. Não considerar estas práticas pode conotar com desrespeito a dignidade e valores da pessoa eferma. Portanto, a prática de cuidado entre os profissionais da saúde necessariamente precisa incluir a espiritualidade/religiosidade como uma conduta ética, que valoriza todas as dimensões da pessoa enferma, sua dimensões biopsicossocial e e espiritual.

d) A AF apontou que a formação e o conhecimento sobre a religiosida-de/espiritualidade pode ajudar os profissionais da saúde a reconhecer a necessida-de espiritual e religiosa da pessoa enferma e identificar se estes gostariam de trazer isso para o tratamento. Aponta-se a importância de uma formação contínua, ética e integral na área 
saúde, tais como, o entendimento sobre a espiritualidade e a religiosidade e suas implicações no modo de viver, e nas tomadas de decisões referentes ao estado de saúde-doença, que pode ajudar a diminuir os conflitos morais entre as questões religiosas, espirituais e a saúde, como por exemplo, quando a pessoa enferma religiosa não aderir a um determinado tratamento médico devido a crença moral religiosa, ou quando o coping religioso espiritual negativo ocorrer por falta de orientação e preparo dos profissionais da saúde em lidar e compreender as crenças religiosas e espirituais da pessoa enferma.

e) No fator 4 existem duas perguntas que tratam sobre a atução e o ecaminhamento da pessoa enferma ao pastoralista/capelão. Um profissional preparado para abordar as questões espirituais e religiosas da pessoa enferma e dos profissionais da saúde. Neste sentido, e a prática do cuidado do pastoralista/capelão aos profissionais da saúde ocorre pelo cultivo da espiritualidade e da ética, que buscam manifestar comunhão, esperança e confiança, e consolo e sentido de vida em meio aos conflitos, dilemas, como um prognóstico negativo ao paciente ou lidar como óbito. Em muitas destas experiências há um sentimento de fracasso por não ter preservado a vida, ou de espelho e projeção imagem de si próprio na mesma situação. Por isso, os profissionais da saúde precisam de um acompanhamento oferecido pelo pastoralista/ capelão.

Em um terceiro momento, considera-se que os resultados da presente pesquisa, estão de acordo com a literatura que aponta que o cuidado técnico-científico em saúde está se transformando em um novo modelo que toma como base a abordagem o bio-psico-socialespiritual, levando em consideração a complexidade do estado de saúde humano (Larimore, 2001, Panzini et al., 2007.)

A dimensão espiritual influencia a saúde, e desta forma, reforçam a importância do profissional de saúde em buscar alívio do sofrimento do paciente, prestando os serviços necessários à esta tarefa e levando em conta as crenças e necessidades do paciente, independente do que acreditam os profissionais de saúde (Peres et al., 2007).

Esta prática só se torna possível, a medida que desde a formação, os profissionais sejam conscientizados de seu compromisso de cuidado integral e que não haja a hierarquização de cuidados baseada em tecnologias pesadas, mas, na prática centrada no paciente. E a atuação nos contextos de saúde sejam baseados pela ética, o que significa associar a prática da espiritualidade nos serviços em saúde, à ações baseadas em valores morais como solidariedade e compaixão (Krause et al.. 2002, Fehring et al., 1997).
Estudos como de Luccheti, (2010, 2011) relatam a importância da dimensão espiritual para os pacientes no seu processo de saúde-doença e afirmam o desejo de receber cuidado espiritual em instituições de saúde. Pesquisas demostram bons resultados em pacientes que recebem assistência espiritual, como maior qualidade de vida, maior sobrevida, menos tempo de internação e menor prevalência de transtornos mentais (Luccheti, 2010, Guimarães, 2007).

Diante o exposto acima, salienta-se a importância da mudança de paradigma de cuidado em saúde, com a inclusão da espiritualidade/religiosidade como prática e reflexão dos profissionais de saúde. É fato que a maioria destes profissionais não estão familiarizados com o tema, pois o mesmo não foi introduzido em seu ambiente de formação universitária (Moreira-Almeida, et al., 2006, Lucchetti, 2010). E embora os dados da presente pesquisa mostrem aproximação e reconhecimento dos profissionais sobre a temática, o estudo de Mariotti (2011) mostrou que 90\% dos médicos, por exemplo, se declararam não preparados pela universidade para atuarem nesta área.

Os aspectos que envolvem as questões religiosas pessoais daquele a quem se cuidam, e como isso está embarcado no cuidado espiritual, necessita ser inseridos no entendimento da prática clínica do médico de forma mais ética. Neste sentido, o respeito aos valores do paciente é fundamental para o vínculo entre o profissional e o paciente.

O presente estudo estudo evidenciou a aproximação da população pesquisada com o tema da espiritualidade/religiosidade no contexto de cuidado em saúde, demonstrando uma concepção que está de acordo com os princípios bioéticos na atenção à saúde e a assistência integral em saúde. Porém, é importante que se aprofunde e amplie a pesquisa a respeito da prática destes profissionais, para que mais dados sejam analisados e as ações sejam avaliadas. Portanto, consideram-se necessárias novas pesquisas das áreas da religião e da saúde com métodos quantitativos e qualitativos sobre assuntos encontrados no decorrer deste estudo, tais como, parâmetros éticos para a integração da espiritualide/religiosidade na formação dos profissionais da saúde; maneiras mais humanizadoras e éticas para a abordagem da espiritualidade/religiosidade no contexto hospitalar; o impacto do coping religioso como a oração no processo de saúde e doença e o impacto negativo da religiosidade no contexto hospitalar na ótica dos conflitos morais causados entre ciência e religião, crença religiosa e tratamento médicos nas tomadas de decisões sobre o estado de saúde e doença; e sobre a prática do cuidado do pastoralista/capelão aos profissionais da saúde através do cultivo da espiritualidade e da ética. 


\section{References Références Referencias}

1. ARTIGAS, Flávio Ricardo Hasten Reiter. Conhecimento e piedade vital: um exercício hermenêutico para a pastoral escolar e universitária e os indicativos para uma teologia da educação. Dissertação (Mestrado) - Escola Superior de Teologia, São Leopoldo, 2008. p. 79.

2. AULETE, Caldas. Dicionário contemporâneo da Língua Portuguesa. 3. ed. Rio de Janeiro: Delta, 1980. v. 5.

3. AZEVEDO, R. "O IBGE e a religião - Cristãos são $86,8 \%$ do Brasil; católicos caem para 64,6\%; evangélicos já são 22,2\%". Disponível em: <http:// veja.abril.com.br/blog/reinaldo/geral/o-ibge-e-a-relig iao-\%E2\%80\%93-cristaos-sao-868-do-brasil-catolic os-caem-para-646-evangelicos-ja-sao-222/> .

Acesso em 29 de julho de 2014.

4. Backes DS, Lunardi VL, Lunardi WDF. A humanização hospitalar como expressão da ética. Rev Latino-Am Enferm. 2006 Jan/Fev; 14(1):132-5.

5. BARDIN, L. Análise de conteúdo. São Paulo: Edições 70, 2011.

6. BATAGLIA, P.U.R. Competência moral: contribuição para a elaboração do constructo. Tese (LivreDocência) - Faculdade de Filosofia e Ciências, Universidade Estadual Paulista, UNESP, Câmpus de Marília, 2020.

7. Beresford, B. A. (1994). Resources and strategies: how parents cope with the care of a disabled child. Journal of Child Psychology and Psychiatry, 35, 171-209.

8. BÍBLIA DE JERUSALÉM. São Paulo: Paulus, 2002.

9. BOFF, L. Ética e moral: a busca dos fundamentos. 2. ed. Petrópolis: Vozes, 2003.

10. BRYMAN, A.; CRAMER. D.Análise de dados em Ciências Sociais: Introdução às técnicas utilizando o SPSS. Oeiras: Celta, 1990.

11. DAMASIO, Bruno Figueiredo. "Uso da análise fatorial exploratória em psicologia". Aval. Psicol., Itatiba, v. 11, n. 2, 2012. Disponível em <http://pe psic.bvsalud.org/scielo.php?script $=$ sci_arttext\&pid $=$ S1677-04712012000200007\&lng $=$ pt\&nrm $=$ iso $>$. Acesso em 23 de setembro de 2014.

12. DERRIDA, Jacques; VATTIMO, Gianni (orgs.). A religião: o seminário de Capri. São Paulo: Estação Liberdade, 2000.

13. ESPINOZA, F. da S.; HIRANO, A. S. "Como dimensões de avaliação dos atributos importantes na compra de condicionadores de ar: um estudo aplicado". Rev. Adm. Contemp., Curitiba, v. 7, n. 4, 2003. Disponível em <http://www.scielo.br/scielo. php?script $=$ sci_arttext\&pid $=$ S1415-655520030004 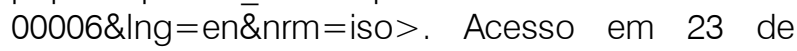 setembro de 2014.
14. GEORGE, D.; MALLERY, P. SPSS for Windows step by step: A simple guide and reference. 11.0 update. Boston: Allyn \& Bacon.

15. GERONE, L. A Espiritualidade/religiosidade na prática do cuidado entre os Profissionais da Saúde.Rev. Inteirações Cultura E Comunidade, Belo Horizonte, V.11 N.20, P. 129-151, Jul./Dez. 2016.

16. GERONE, Lucas Guilherme Teztlaff de. BATAGLIA, Patricia Unger Raphael. A espiritualidade e a moral na prática do docente. Revista Científica Multidisciplinar Núcleo do Conhecimento. Ano 05, Ed. 09, Vol. 01, pp. 108-120. Setembro de 2020. ISSN: 2448-0959, Link de acesso: https://www. nucleodoconhecimento.com.br/ciencia-da-religiao/ pratica-do-docente, DOI: 10.32749/nucleodoconhe cimento.com.br/ciencia-da-religiao/pratica-dodocente

17. GERONE, Lucas Guilherme Teztlaff de. Um olhar sobre a Espiritualidade/religiosidade na Prática do Cuidado entre profissionais de saúde e pastoralistas.Dissertação (Mestrado em Teologia) Escola de Educação e Humanidades. PontifíciaUniversidadeCatólica do Paraná. Curitiba, 2015.

18. Guimarães HP, Avezum A. O impacto da espiritualidade na saúde física. Rev Psiq Clin. 2007; 34(Supl 1): 88-94.

19. HAIR JR., J. H.; BABIN, B.; MONEY, A. H.; et all. Fundamentos de métodos de pesquisa em administração. Porto Alegre: Bookman, 2005.

20. JOB, F. P.P. Os sentidos do trabalho e a importância da resiliência nas organizações. Tese (Doutorado em Administração de Empresas). São Paulo: Fundação Getúlio Vargas, 2003.

21. KOENIG, H. Medicina, religião e saúde: o encontro da ciência e da espiritualidade. Porto Alegre: LMP, 2012.

22. Krause N, Liang J, Shaw BA, et al. Religion, death of a loved one, and hypertension among older adults in Japan. J Gerontol B Psychol Sci Soc Sci. 2002; 57(2):S96-S107.

23. La Taille, Y. (2006). Moral e ética: Dimensões intelectuais e afetivas. Porto Alegre: Artmed, 189 p. 45.

24. Larimore WL. Providing basic spiritual care for patients: should it be the exclusive domain of pastoral professionals? Am Fam Physician. 2001; 63(1): 36,38-40.

25. LEITE, Jussandro Plácido. A ÉTICA ARISTOTÉLICA NA SOCIEDADE BRASILEIRA ATUAL: Perspectiva da Filosofia para o Ensino Médio. Disponível em: $<$ http://www.isepnet.com.br/website/revista/Revista ISEP 01/artigos/jussandro.prn.pdf $>$. Acesso em 24 out 2014.

26. LEVIN, J. Deus, fé e saúde - explorando a conexão espiritualidade-cura. São Paulo: Cultrix, 2003. 
27. LEONE, S.; PRIVITERA, S.; CUNHA, J.T. (Coords.). Dicionário de bioética. Aparecida: Editorial Perpétuo Socorro/Santuário, 2001.

28. Lucchetti G, Granero AL, Bassi RM, et al. Espiritualidade na prática clínica: o que o clínico deve saber? Rev Soc Bras Clín Méd. 2010; 8(2): 154-8.

29. Lucchetti G, Lucchetti AG, Badan-Neto AM, et al. Religiousness affects mental health, pain and quality of life in older people in an outpatient rehabilitation setting. J Rehabil Med 2011; 43(4): 316-22.

30. Lukoff D, Lu F, Turner R. Toward a more culturally sensitive DSM--IV. Psychoreligious and psychospiritual problems. J Nerv Ment Dis. 180(11): 673-82.

31. LUZ, M. Origem etimológica do termo. Diponivel em: <http://www.epsjv.fiocruz.br/dicionario/verbet es/sau.html> . Acesso em 10 de outubro de 2013.

32. Mariotti LG, Lucchetti G, Dantas MF, et al. Spirituality and medicine: views and opinions of teachers in a Brazilian medical school. Med Teach. 2011; 33(4): 339-40.

33. MOREIRA-ALMEIDA A, et al. "Envolvimento religioso e fatores sociodemográficos: resultados de um levantamento nacional no Brasil". Revista de Psiquiatria Clínica v. 37, n. 1, 2010. Disponível em: $<$ http://www.scielo.br/scielo.php?pid=S0101-6083 2010000100003\&script $=$ sci_arttext $>$. Acesso em 29 de setembro de 2013.

34. Moreira-Almeida A, Lotufo Neto F, Koenig HG. Religiousness and mental health: a review. Rev Bras Psiquiatr. 2006; 28(3):242-50.

35. Moreira-Almeida A, Lotufo Neto F, Koenig HG. Religiousness and mental health: a review. Rev Bras Psiquiatr. 2006; 28(3):242-50.

36. Panzini RG, Rocha NS, Bandeira DR, et al. Qualidade de vida e espiritualidade. Rev Psiquiatr Clín. 2007; 34(Suppl 1):105-15.

37. PANZINI, R. Escala de coping religioso-espiritual (escala cre). Dissertação de Mestrado em Psicologia. Porto Alegre: Universidade Federal do Rio Grande do Sul, 2004.

38. PEREIRA, A. Guia prático de utilização do SPSS: Análise de dados para Ciências Sociais e Psicologia. Lisboa: Sílabo, 2006.

39. Peres MF, Arantes AC, Lessa PS, et al. A importância da integração da espiritualidade e da religiosidade no manejo da dor e dos cuidados paliativos. Rev Psiquiatr Clín. 2007; 34(Suppl 1): 82-7.

40. PUCHALSKI, C. M. "Espiritualidade e medicina: os currículos na educação médica". Journal of Education Câncer: O Jornal Oficial da Associação Americana para a Educação do Câncer, 21 (1), pp. 14-18, 2006.
41. SCLIAR, M. "Histórico do conceito de saúde". PHYSIS: Rev. Saúde Coletiva, Rio de Janeiro, n. 17, v. 1, pp. 29-41, 2007.

42. SOUZA, W. "A espiritualidade como fonte sistêmica na Bioética". Rev. PistisPrax., Teol. Pastor., Curitiba, v. 5, n. 1, pp. 91-121, jan./jun. 2013.

43. TEIXEIRA, F. "O potencial libertador da espiritualidade e da experiência religiosa". In: AMATUZZI, M. M. Psicologia e espiritualidade. São Paulo: Paulus, 2005.

44. TURATO, Egberto Ribeiro. "Métodos qualitativos e quantitativos na área da saúde: definições, diferenças e seus objetos de pesquisa".Rev.Saúde Pública, São Paulo, v. 39, n.3, jun. 2005.Disponível em: $\quad<$ http://www.scielo.br/scielo.php?script=sci arttext\&pid=S0034-89102005000300025\&Ing =en\& nrm=iso $>$.Acesso em 27 de novembro de 2014. 